\title{
Analysis of Ignitions Following 2011 Tohoku Earthquake Using Kawasumi Model
}

\author{
KEISUKE HIMOTO ${ }^{1}$, MASUMI YAMADA ${ }^{1}$, and TOMOAKI NISHINO ${ }^{2}$ \\ ${ }^{1}$ Disaster Prevention Research Institute, Kyoto University \\ Gokasho, Uji, Kyoto 6110011, Japan \\ 2 Department of Architecture, Kobe University \\ Rokkodai 1-1, Nada, Kobe, Hyogo 6578501, Japan
}

\begin{abstract}
Ignitions following the Tohoku earthquake (2011) can be divided either into earthquake-generated ignitions or tsunami-generated ignitions. This study analyzed the behavior of the earthquake-generated ignitions. Ignition records of 698 municipalities of eastern Japan was collected by a questionnaire survey and found that 191 ignitions were either directly or indirectly caused by seismic motion. These records of earthquakegenerated ignition were analyzed using the statistical model proposed by Kawasumi (Kawasumi model). Kawasumi model is a simple one-parameter model which formulates the relationship between the ignition probability $p$ and the scale of seismic intensity $\theta$. Seismic indices $\theta$ used in this analysis were (a) collapse ratio of houses, (b) JMA (Japan Meteorological Association) seismic intensity, (c) PGA (peak ground acceleration), (d) PGV (peak ground velocity), (e) PGD (peak ground displacement), (f) acceleration response and (g) SI (Spectral Intensity). Obtained adjusted determination coefficients were higher than 0.7 for most of the seismic indices $\theta$ except for (a) collapse ratio of houses and (e) PGD. After normalization with regard to time and season of its occurrence, the results were further compared with that of various earthquakes (1927-1968), and the Kobe earthquake (1995). Ignition probability $p$ of the Tohoku earthquake (2011) was substantially lower than that of the various earthquakes (1927-1968). On the other hand, the difference of ignition probability $p$ between the Tohoku earthquake (2011) and Kobe earthquake (1995) was relatively small.
\end{abstract}

KEYWORDS: 2011 Tohoku earthquake, post-earthquake fire, ignition, statistical model

\section{INTRODUCTION}

The Tohoku Earthquake, officially named "The 2011 off the Pacific coast of Tohoku Earthquake [1]" occurred on March $11^{\text {th }}, 2011$ caused significant damage mainly in eastern part of Japan. The epicenter of the earthquake was about $130 \mathrm{~km}$ off-shore of the Pacific coast of Japan with the fault rupture area of $200 \mathrm{~km}$ times $500 \mathrm{~km}$. Estimated moment magnitude of this earthquake was 9.0, which is the largest among the recorded history of this country. Wide area of eastern Japan was subjected to severe shaking which caused substantial damage of structures, landslide in mountain areas, and liquefaction of filled-up grounds. In addition to the shaking, large deformation of the ocean bed around the fault rupture area generated huge tsunamis which swept away the cities and settlements along the Pacific coast. Distance along the coast line struck by the tsunamis with inundation height of over $10 \mathrm{~m}$ was as long as $530 \mathrm{~km}$. As a consequence, overall number of collapsed houses and other structures was 128,801 and 96,529 respectively, and that of fatalities including missing persons counted 21,176 [2].

In the Tohoku earthquake, major physical damage in the affected area was caused by the tsunamis. However, damage by fires was also considerable; reported number of ignitions was as many as 330 [2]. Part of the ignitions enlarged and expanded the damage of earthquake- and tsunami-struck areas. Earthquakes which involved several ignitions did occur in the last decades. However, such a large number of ignitions have not been observed ever since 1994 Northridge earthquake which involved 110 ignitions [3], and 1995 Kobe earthquake which involved 293 ignitions [4]. Thus, the ignition record of the Tohoku earthquake is a valuable database which enables analysis of ignition behavior from various perspectives.

In this study, features of ignitions and seismic motion observed in 2011 Tohoku earthquake event was overviewed. Ignition behaviors were analyzed using the statistical model proposed by Kawasumi (Kawasumi model) in comparison with those of historical earthquake events including 1995 Kobe earthquake. One of the features of ignitions following 2011 Tohoku earthquake is that it involved a large number of tsunami-generated ignitions in addition to the ordinary earthquake-generated ignitions. Although 
occurrence of tsunami-generated ignitions is a matter of concern in future earthquakes, this study focuses on the analysis of earthquake-generated ignitions.

\section{OVERVIEW OF IGNITIONS FOLLOWING 2011 TOHOKU EARTHQUAKE}

FDMA (Fire and Disaster Management Agency) issued an interim report on the damages and losses caused by 2011 Tohoku earthquake and tsunami; it shows that there were 330 earthquake- and tsunami-generated ignitions in total [2]. However, because the report only provides the number of ignitions observed at each municipality, additional survey was necessary in order to obtain information of individual ignitions. Thus, an investigation team including one of the authors of this paper was established under JAFSE (Japan Association for Fire Science and Engineering) for collecting detailed ignition records from the affected municipalities. In 2012, the team conducted a questionnaire survey for all the fire services in 17 prefectures of Eastern Japan including Aomori, Iwate, Akita, Miyagi, Yamagata, Fukushima, Tochigi, Gunma, Ibaraki, Saitama, Chiba, Tokyo, Kanagawa, Yamanashi, Niigata, Nagano, and Shizuoka. Target area of the questionnaire survey is enclosed by a heavy line in Fig.1. The questionnaire survey requested the fire services to report detailed information of all the ignitions (including zero ignitions) that occurred between March 11st and April 11st of 2011, which is the period of one month following the earthquake. Items of ignition record include the ignition location, whether it is within the tsunami-inundated area or not, estimated occurrence time, reported time, estimated cause, type of fire, consequent losses, how firefighting activity was conducted, etc.. Eventually, 258 out of 297 fire services (86.9\%) responded to this questionnaire survey. As a result, 2,730 ignition records of 698 municipalities in eastern Japan were collected; the coverage area is colored in gray in Fig.1. According to the 2010 Census, overall population within the coverage area is 46.9 million, and that of number of household is 19.0 million.

Result of the questionnaire survey showed that the number of ignitions either directly or indirectly generated by seismic motion was 191, and those generated by tsunami was 163 . Locations of both earthquake- and tsunami-generated ignitions are plotted in Fig.1. Total number of ignitions was 354, which

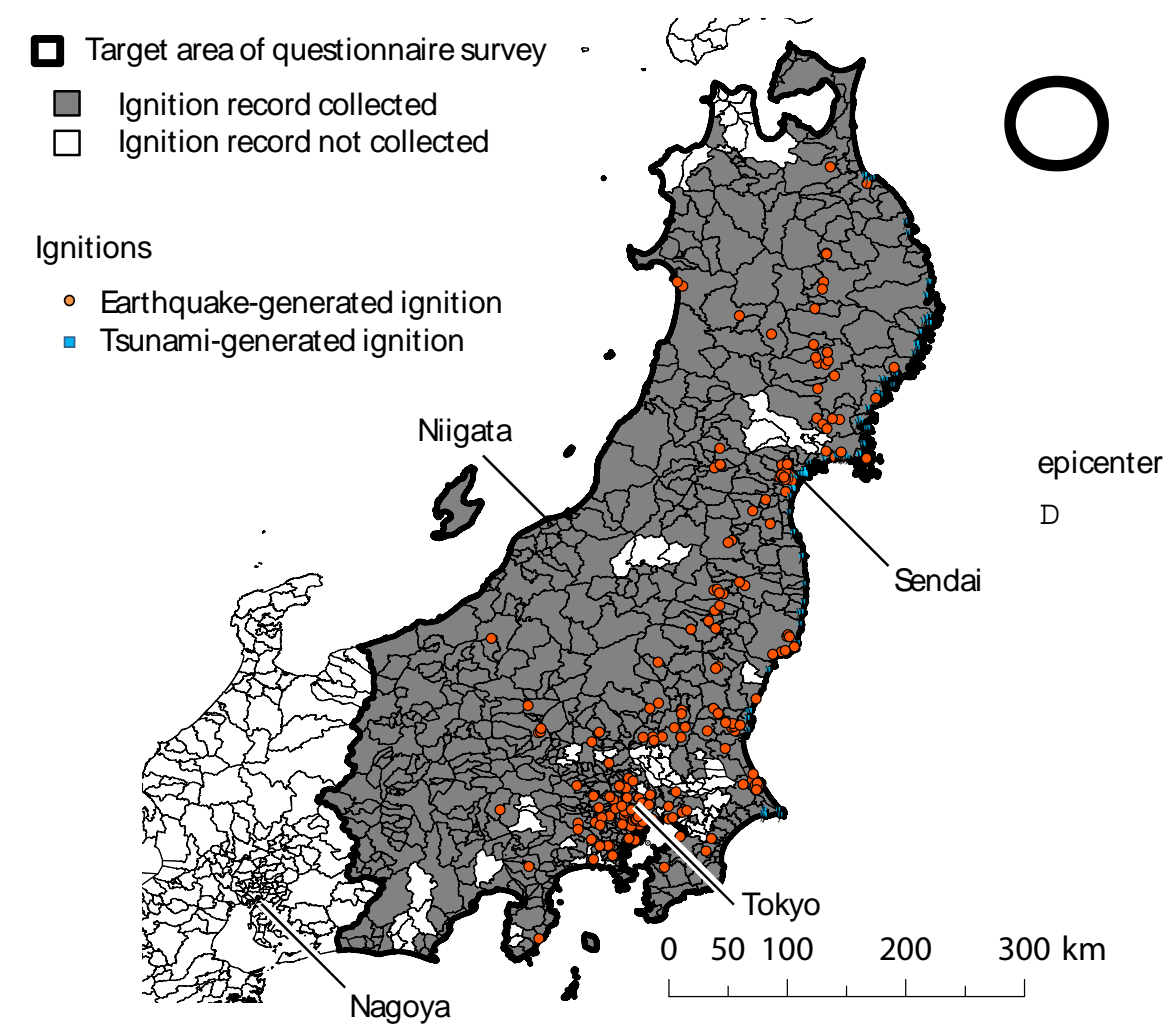

Fig. 1. Target area of the questionnaire survey and reported ignition locations. 
is $13.0 \%$ of all the reported ignitions. Note that the actual number of ignitions should be more than 354 , because the rate of the response was $86.9 \%$. However, note that the number 354 is slightly bigger than 330 reported by FDMA [1]. This is because the procedure of counting ignition was different between the JAFSE questionnaire survey and the FDMA report. As for the questionnaire survey, relevance of the reported ignitions to seismic motion or tsunami was subjectively judged by the members of the JAFSE investigation team based on the ignition causes reported by the fire services. On the other hand, FDMA summed up the numbers of ignition individually reported by the fire services. Relevance of the ignitions to seismic motion or tsunami was judged by the correspondent fire service.

Number of earthquake- and tsunami-generated ignitions reported during 10 days subsequent to the main shock is shown in Fig.2. For comparison, number of ignitions of 1995 Kobe earthquake is added to it. There is no outstanding difference between the three cases. For all the cases, number of ignitions was the

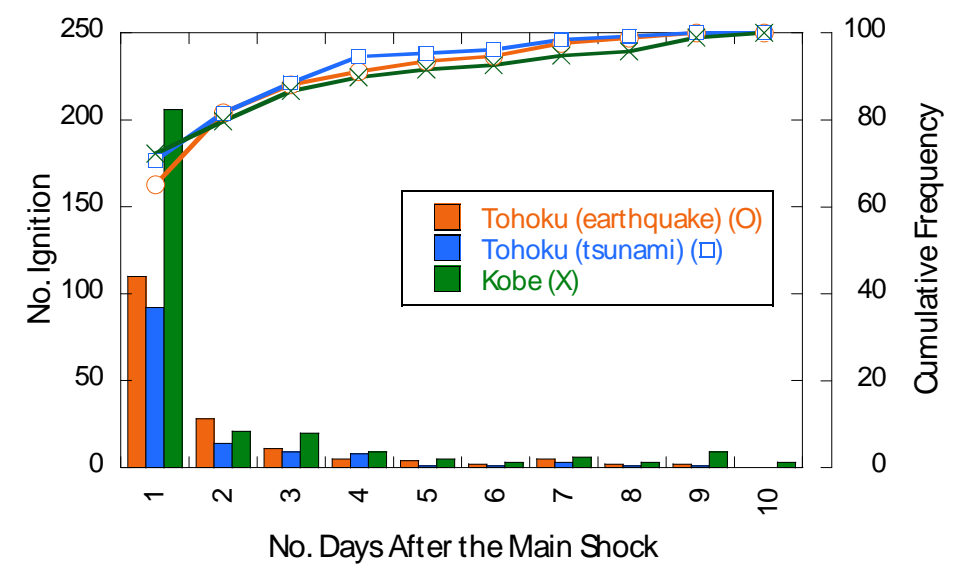

Fig. 2. Number of ignitions in 10 days subsequent to the main shock.

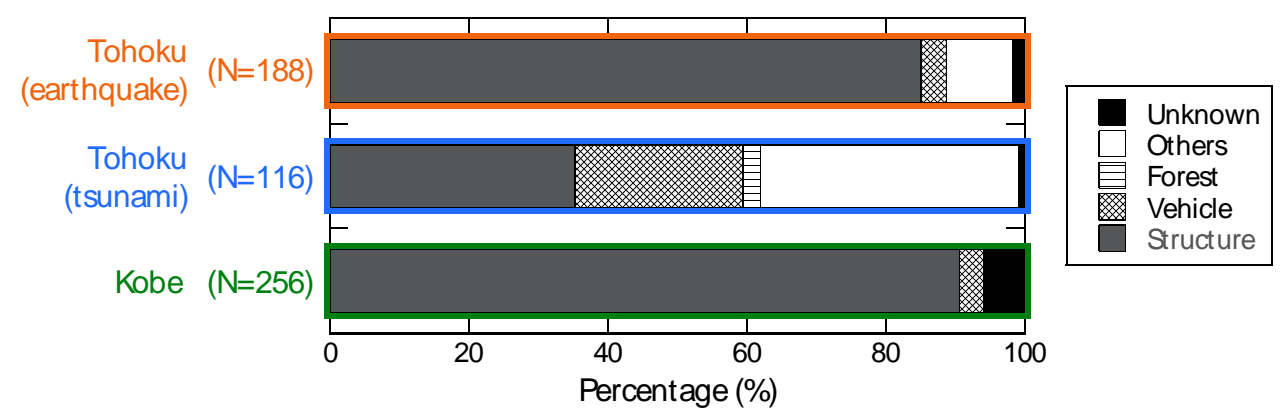

Fig. 3. Type of fire observed in 10 days subsequent to the main shock.

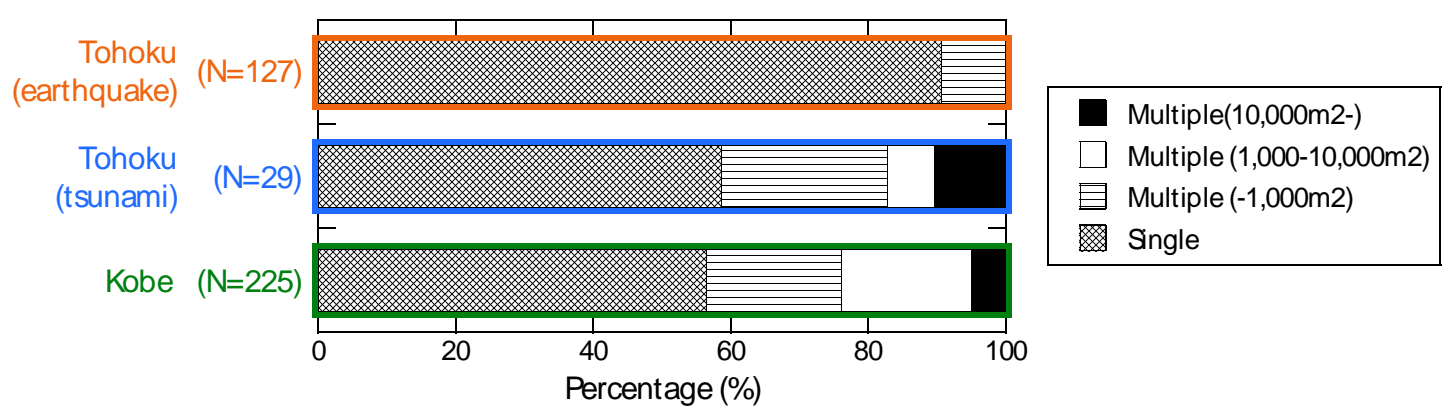

Fig. 4. Overall burnt floor area in one "structure" fire in 3 days subsequent to the main shocks. 
maximum in the first day; the proportion was between $65-73 \%$ of all the ignitions during 10 subsequent days. However, note that occurrence of the Tohoku earthquake was 14:46 in the afternoon, whereas that of the Kobe earthquake was 5:46 in the morning. Thus, actual duration of the first day was about 9 hours for the Tohoku earthquake and about 18 hours for the Kobe earthquake. Number of ignitions steeply decreased in the second day that the daily proportion was between $7-17 \%$ of all the ignitions. From then on, the daily proportion of the number of ignition decreased more or less monotonically.

Proportion of fire types is displayed in Fig.3. Numbers of relevant ignitions were 188 for the Tohoku earthquake (earthquake-generated), 116 for the Tohoku earthquake (tsunami-generated), and 256 for the Kobe earthquake. Among several fire types, proportion of "structure" fire exceeded $80 \%$ for earthquakegenerated ignitions of both the Tohoku and Kobe earthquakes. On the other hand, proportion of "structure" fire for tsunami-generated ignitions was only 35\%. Alternatively, proportions of "vehicle" fire and "others" were relatively high. One of the major features of tsunami-generated ignitions in the Tohoku earthquake is that there were a substantial number of witnesses on fires started when tsunami-drifted vehicles crashed each other. The crash generally accompanied huge blast sound, which suggests that the fires were caused either by short-circuit of damaged electrical system or escape of flammable material from damaged fuel tank. However, note that the type "others" includes fires of complex types. There were many fires which started among a heap of drifted vehicles. However, some of them were not grouped into "vehicle" fires because they subsequently extended to nearby structures or forest due to the limited availability of firefighting resources.

One of the major differences between the Tohoku and Kobe earthquakes is that the size of one "structure" fire of the Tohoku earthquake was substantially smaller than that of the Kobe earthquake. Overall burnt floor areas of fires occurred within 3 days subsequent to the main shock are compared in Fig.4. Numbers of relevant ignitions were 127 for the Tohoku earthquake (earthquake-generated), 29 for the Tohoku earthquake (tsunami-generated) and 225 for the Kobe earthquake. As for earthquake-generated ignitions of the Tohoku earthquake, $91 \%$ of ignitions were extinguished before spread to adjacent buildings. On the other hand, relevant proportion of the Kobe earthquake was $56 \%$, and the rest of the fires involved multiple buildings. As may be remembered, there were several conflagrations in the middle of Kobe city in the event of the Kobe earthquake. Fires with overall burnt floor area exceeded $10,000 \mathrm{~m}^{2}$ was $5 \%$ of all "structure" fires. One major reason for this difference is the distribution density of ignition; while 191 ignitions distributed over 109 municipalities in the Tohoku earthquake (1.8 ignitions/municipality), 285 ignitions concentrated in 38 municipalities in the Kobe earthquake ( 7.5 ignitions/municipality). The proportion of overall burnt floor area for tsunami-generated ignitions is similar to that of the Kobe earthquake, because several tsunami-generated ignitions became conflagrations. Failure of extinguishment is attributed to the difficulty in conducting firefighting activity in tsunami-inundated areas.

\section{OVERVIEW OF SEISMIC MOTION OF 2011 TOHOKU EARTHQUAKE}

The strong motion of the Tohoku earthquake was recorded by the national seismic networks (K-NET, KiKnet, and Japan Meteorological Agency). The station spacing is about $20 \mathrm{~km}$, and the seismic intensity was directly computed from the waveform records. Most of the national seismic networks was implemented after 1995 Kobe earthquake. During the Kobe earthquake, limited number of seismic stations was available, and most of seismic intensities were measured by human sense and damage of structures. Due to the requirement of rapid emergency response after a large earthquake, strong shaking information needs to be collected immediately. In response to this, JMA started to develop seismic stations sending strong motion information in real time, and redefined JMA seismic intensity computed from the strong motion records. The new definition of seismic intensity has been used since October 1996. The national seismic network (K-NET, KiK-net, etc) were developed by National Research Institute for Earth Science and Disaster Prevention within 2 years after the Kobe earthquake. These data can also be used for research purposes.

During the Tohoku event, the region recording strong shaking (PGV of over $80 \mathrm{~cm} / \mathrm{s}$ ) extended from Iwate to Ibaraki prefecture as shown in Fig.5 due to the large rupture dimension. On the other hand, the strong shaking area of the Kobe earthquake was limited in the near-source region. JMA seismic intensity 6 or 7 was recorded only within $20 \mathrm{~km}$ from the ruptured fault. Although the region of strong shaking for the Kobe earthquake was relatively small, the damage of the structure was significant. JMA seismic intensity 7 was recorded in Kurihara city during the Tohoku earthquake. However, building damages were all minor, and none of them was totally collapsed. Relationship between PGV and collapse ratio of houses is depicted in 
Fig.6. Note that the records of tsunami-affected municipalities are excluded in this figure, because number of houses collapsed by tsunami was not discernible from that collapsed by ground motion. The difference of damage was due to the frequency content in the ground motion. Ground accelerations and acceleration response spectra recorded at JMA Kobe Marine Observatory for the Kobe earthquake and K-NET Tsukidate for the Tohoku earthquake are shown in Figs. 7 and 8. During the Kobe earthquake, a pulse-like waveform with 1-2 seconds was generated due to the directivity and predominant period of the size of the earthquake. This period strongly affects the damage of structures. For the Tohoku earthquake, short period ground motion (less than 0.5 seconds) was dominant and the ground motion with period of 1-2 seconds were relatively small. Therefore, the structural damage was not very severe as expected from the seismic intensity [5].

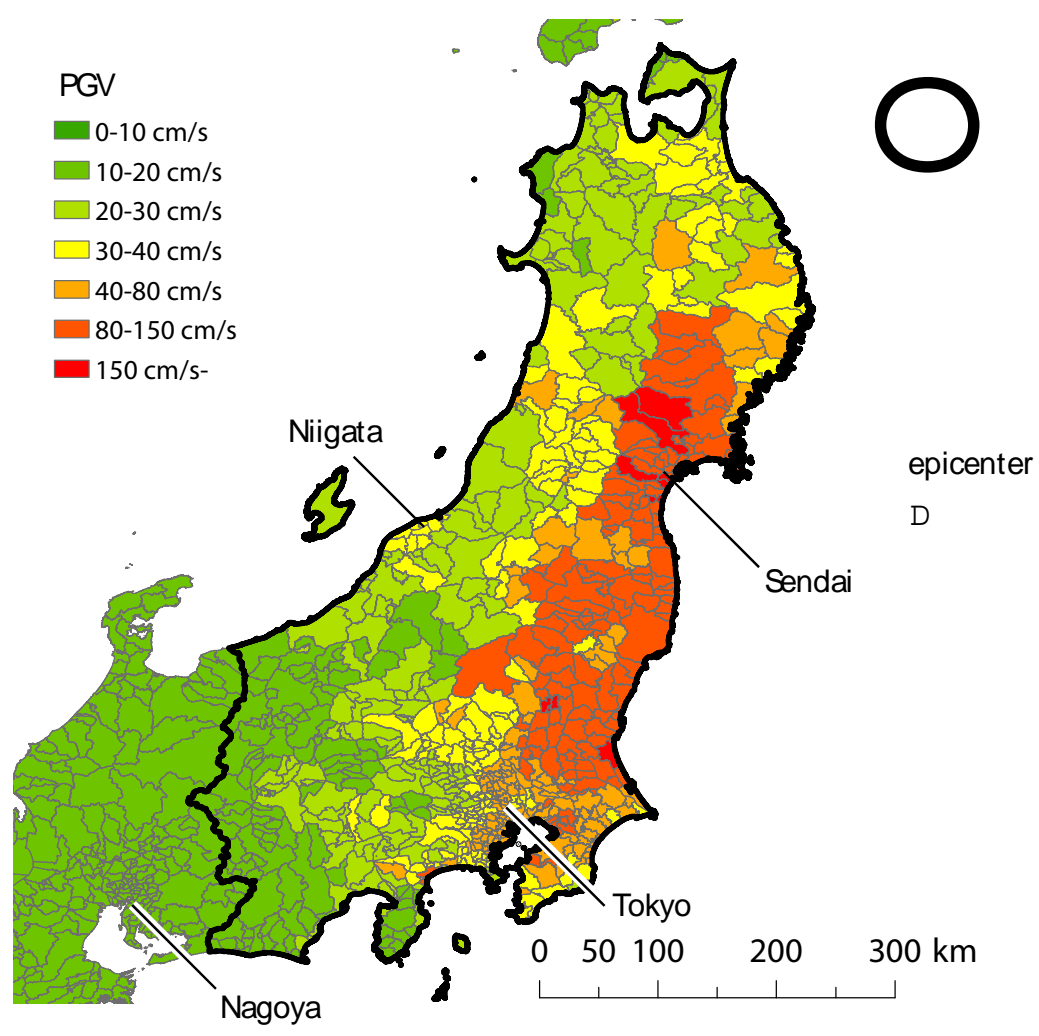

Fig. 5. Recorded PGV of the main shock.

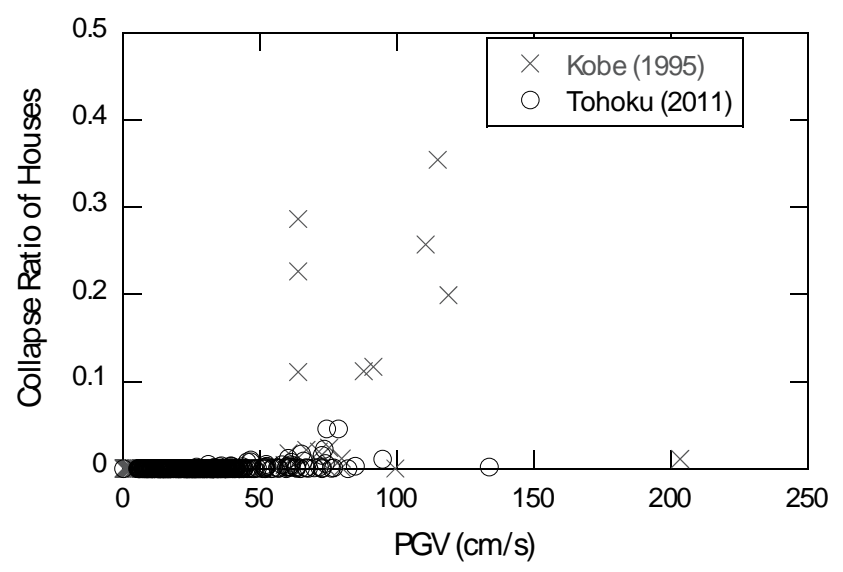

Fig. 6. PGV and collapse ratio of houses. 


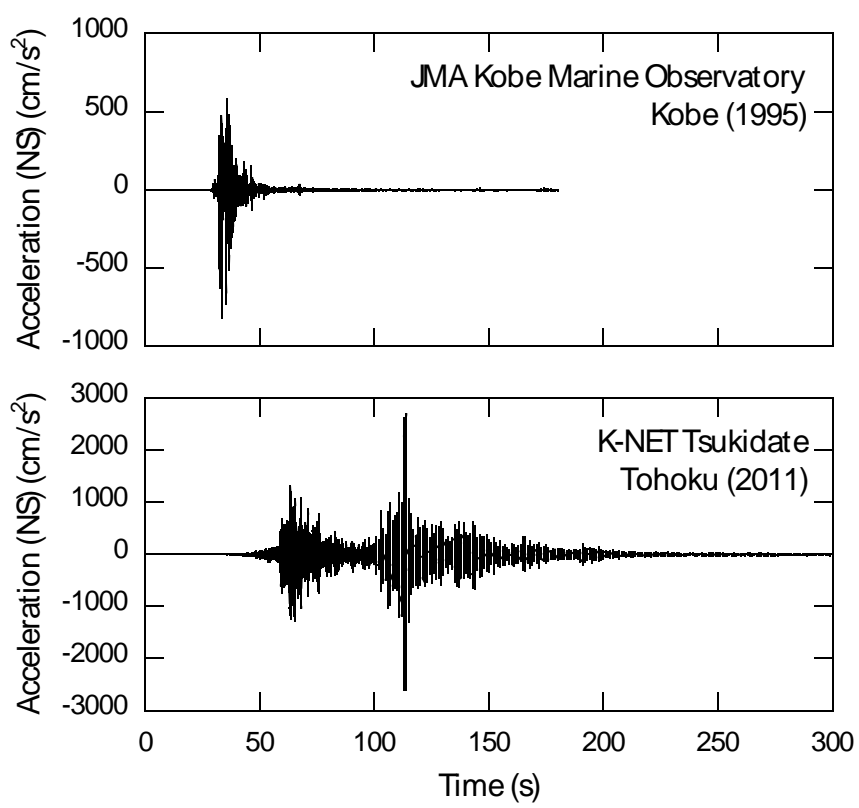

Fig. 7. Acceleration records of the Kobe and Tohoku earthquakes.

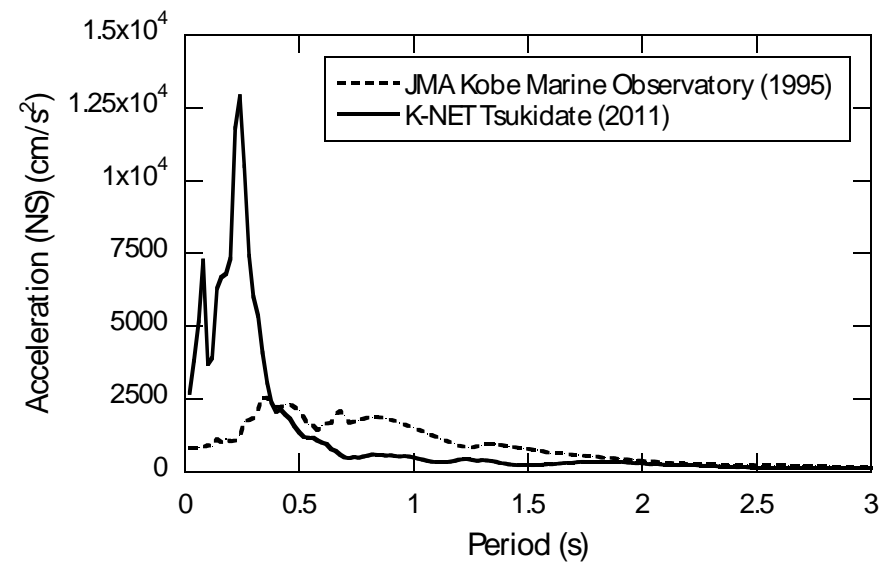

Fig. 8. Acceleration response spectra of the Kobe and Tohoku earthquakes.

\section{ANALYSIS OF IGNITION USING KAWASUMI MODEL}

Mechanism of earthquake-generated ignition is essentially diverse; it may be caused by turnover of heating and cooking appliances, shortcut of damaged electrical wiring, use of open flame in the midst of blackout, and others. However, it is empirically known that ignition probability $p$ which is conventionally defined as,

$p=\frac{N_{\text {ignition }}}{N_{\text {household }}}$

is in certain correlation with the scale of ground motion $\theta$. Note that $N_{\text {ignition }}$ is the number of ignition, and $N_{\text {household }}$ is the number of household, both for a unit municipality or a group of municipalities. One of the earliest models for ignition probability $p$ is proposed by Kawasumi which takes the form of, 
where $A$ and $B$ are the coefficients [6]. Kawasumi first applied his model to the Kanto earthquake data with the collapse ratio of houses as the scale of ground motion $\theta$. However, his proposal was rather conceptual and the coefficients and goodness-of-fit value were not indicated. Originally, this correlation was deduced empirically. However, Aoki proved that it is equivalent to a model which evaluates the ignition probability $p$ by comparing the metaphysical scales of seismic intensity $S$ and resistance to ignition $R$, with the extreme distributions assumed for both $S$ and $R$ [7]. Because Kawasumi model can reasonably correlate actual ignition records with a relatively simple expression, it has widely been used for practice of post-earthquake fire loss estimation from then on. However, at the same time, several attempts have also been made on improving the goodness-of-fit of Kawasumi model. Mizuno proposed an extension of Kawasumi model by modifying the coefficient $A$ in Eq.(2) as follows [8][9],

$A \propto \alpha \beta$

where $\alpha$ is the time correction factor based on the usage rate of cooking and heating appliances at the occurrence of an earthquake, $\beta$ is the season correction factor based on the monthly number of ignitions in this country, and $C$ is another coefficient. Mizuno determined the coefficients using ignition records of 13 historical earthquakes including 1923 Kanto earthquake with the collapse ratio of houses as the scale of ground motion $\theta$. He reported that the correlation coefficient was 0.743 for the summer season model and 0.908 for the winter season model.

\section{Seismic Indices $\theta$ Used in the Analysis}

Kawasumi model is a single-parameter model which explains the correlation between ignition probability $p$ and a seismic index $\theta$. After the development of the national seismic network since 1996, raw seismic waveforms become available which enabled choice of various seismic indices $\theta$. In this analysis, correlation between ignition probability $p$ and seismic indices $\theta$ of the Tohoku earthquake were analyzed. Overviews of target municipalities for the Tohoku earthquake and Kobe earthquake are summarized in Tables 1 and 2, respectively. Selected seismic indices $\theta$ are, (a) collapse ratio of houses, (b) JMA (Japan Meteorological Agency) seismic intensity, (c) PGA (Peak Ground Acceleration), (d) PGV (Peak Ground Velocity), (e) PGD (Peak Ground Displacement), (f) acceleration response $(0.5 \mathrm{~s}, 1.0 \mathrm{~s}, 1.5 \mathrm{~s}$, and $2.0 \mathrm{~s})$, and (g) SI (Spectral Intensity). However, due to the limited availability of seismic record, correlation with only (a) collapse ratio of houses and (d) PGV were investigated for the ignition probability $p$ of the Kobe earthquake. Correlation with (b) JMA seismic intensity was not investigated because ignitions were observed only at municipalities with JMA seismic intensity of 7 in the Kobe earthquake except for one municipality.

\section{(a) Collapse ratio of houses}

Collapse ratio of houses is the percentage of number of collapsed houses to total number of houses in the corresponding municipality. Numbers of collapsed houses for both earthquakes were cited from the report of FDMA [2][4]. However, because the number of collapsed houses for the Tohoku earthquake includes houses swept away by the tsunami which are not discriminated from those damaged by shaking, municipalities affected by tsunami was excluded from this analysis. As a result, number of ignitions due to shaking which could be used in the analysis was 159 . Total number of houses for both earthquakes was taken from the statistical report of Housing and Land Survey, a national survey conducted every 5 years.

(b) JMA (Japan Meteorological Agency) seismic intensity

JMA seismic intensity categorizes the seismic scale into 10 sequential scores of 0 to 7 (level 5 and 6 are further divided into lower and upper, respectively). Since the beginning of observation in 1884, JMA has determined the intensity level by human sense. Because of this, record of JMA seismic intensity is available only at limited sites for the Kobe earthquake. However, JMA started to develop seismic stations directly measuring seismic intensity since 1996. Currently, about 4,200 seismic stations are working all over Japan in 2009. 
Data from the seismic networks K-NET, KiK-net and JMA were used for evaluating PGA, PGV, PGD, acceleration response, and SI. A representative value of each municipality was computed from the all stations within $50 \mathrm{~km}$ of the government office with distance weighting. Vector sum of the maximum of three components (NS, EW and UD) was used for the PGA.

\section{(d) PGV (Peak Ground Velocity)}

Velocity waveforms of the the Tohoku earthquake were computed from the acceleration waveforms by the integration in time domain. The records were low-pass filtered by $4^{\text {th }}$ order Butterworth filter with corner frequency $0.05 \mathrm{~Hz}$ [10]. Vector sum of the maximum of three components (NS, EW and UD) was used for the PGV. For the Kobe earthquake, seismic data was recorded only at limited sites. Thus, PGV of each municipality was estimated using a ground motion attenuation model with the fault distance, and multiplied by the amplification in the subsurface layer [11][12].

(e) PGD (Peak Ground Displacement)

Displacement waveforms were computed from the acceleration waveforms by the integration twice in time domain. The records were low-pass filtered by $4^{\text {th }}$ order Butterworth filter with corner frequency $0.05 \mathrm{~Hz}$. Vector sum of the maximum of three components (NS, EW and UD) was used for the PGD.

(f) Acceleration response $(0.5 \mathrm{~s}, 1.0 \mathrm{~s}, 1.5 \mathrm{~s}$, and $2.0 \mathrm{~s})$

Acceleration response represents the response of a single degree of freedom system with the damping of $5 \%$. Root-mean-square of two horizontal components (NS and EW) was used for the values. Four representative periods $(T=0.5,1.0,1.5$, and $2.0 \mathrm{~s})$ are used. It is well known that the acceleration response with period shorter than 1 second has a good correlation with sensible seismic intensity, damage inside building, or that of non-structural members such as roof tiles. On the other hand, the acceleration response with period 1-2 seconds has good correlation with damage of structural members [5].

Table 1. Overview of target municipalities (2011 Tohoku earthquake).

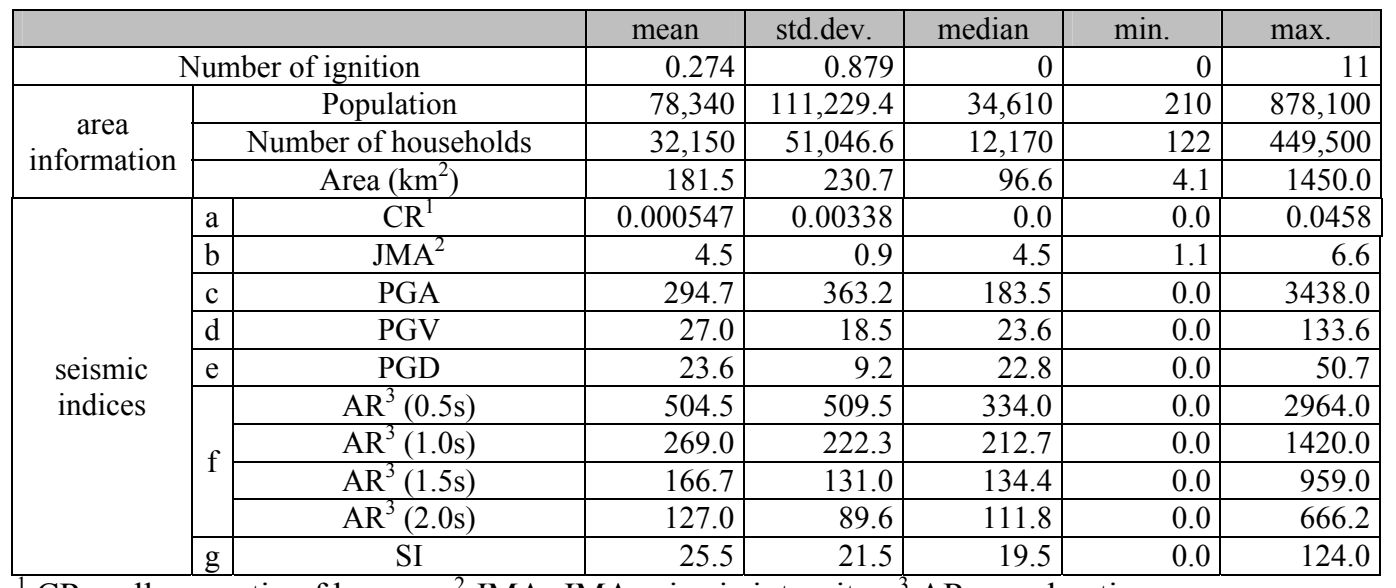

${ }^{1} \mathrm{CR}$ : collapse ratio of houses ${ }^{2}$ JMA: JMA seismic intensity ${ }^{3}$ AR: acceleration response

Table 2. Overview of target municipalities (1995 Kobe earthquake).

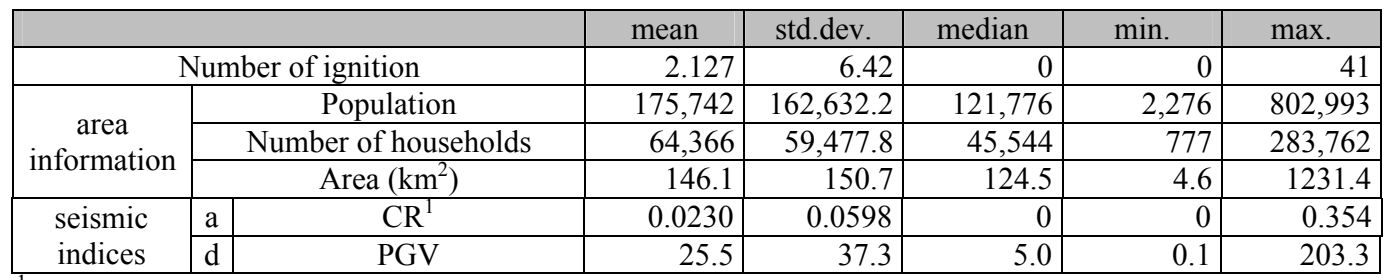

${ }^{1}$ CR: collapse ratio of houses 
(g) SI (Spectral Intensity)

SI is defined as the area under the pseudo-velocity response spectrum, over the period range 0.1 to $2.5 \mathrm{sec}$ [13]. It has a good correlation with structural damage. The definition is;

$S I=\frac{1}{2.4} \int_{0.1}^{2.5} S_{V} d t(\mathrm{~cm} / \mathrm{s})$

where $S_{V}$ is the pseudo-velocity response spectrum, and $t$ is the time. Root-mean-square of two horizontal components (NS and EW) was used as SI value. In Japan, gas companies use SI as one of the criteria to shut off gas pipes [14].

\section{Applicability of Kawasumi Model}

Coefficients $A$ and $B$ of Kawasumi model in Eq.(2) was obtained by the regression analysis. However, because of the formulation of Kawasumi model which contains logarithmic terms on both sides of the equation, records of zero-ignition and zero-seismic-intensity need to be omitted from the samples. Use of such biased samples may incorrectly evaluate the ignition probability $p$. In order to avoid this, seismic indices $\theta$ were categorized into several classes with certain intervals so that the numbers of sample in respective classes are in the same rage. Thus, records of zero-seismic-intensity were included in the class of the lowest seismic intensity $\theta$; those of zero-ignition were also incorporated into the analysis by summing up the numbers of household on the corresponding class of seismic intensity $\theta$. However, at the same time, there is a cost of the grouping that it involves a certain reduction of data accuracy, i.e., an area is no more represented by a single seismic intensity value, which is considered as a limitation of Kawasumi model. As a result of the grouping, the number of data points eventually used in this analysis was 4 for CR (collapse ratio of houses) and 6 for PGV of the Tohoku earthquake; 5 for CR and 6 for PGV of the Kobe earthquake. Note that median values were used as the representative values of each class of seismic intensity $\theta$.

Table 3. Results of the regression analysis (2011 Tohoku earthquake).

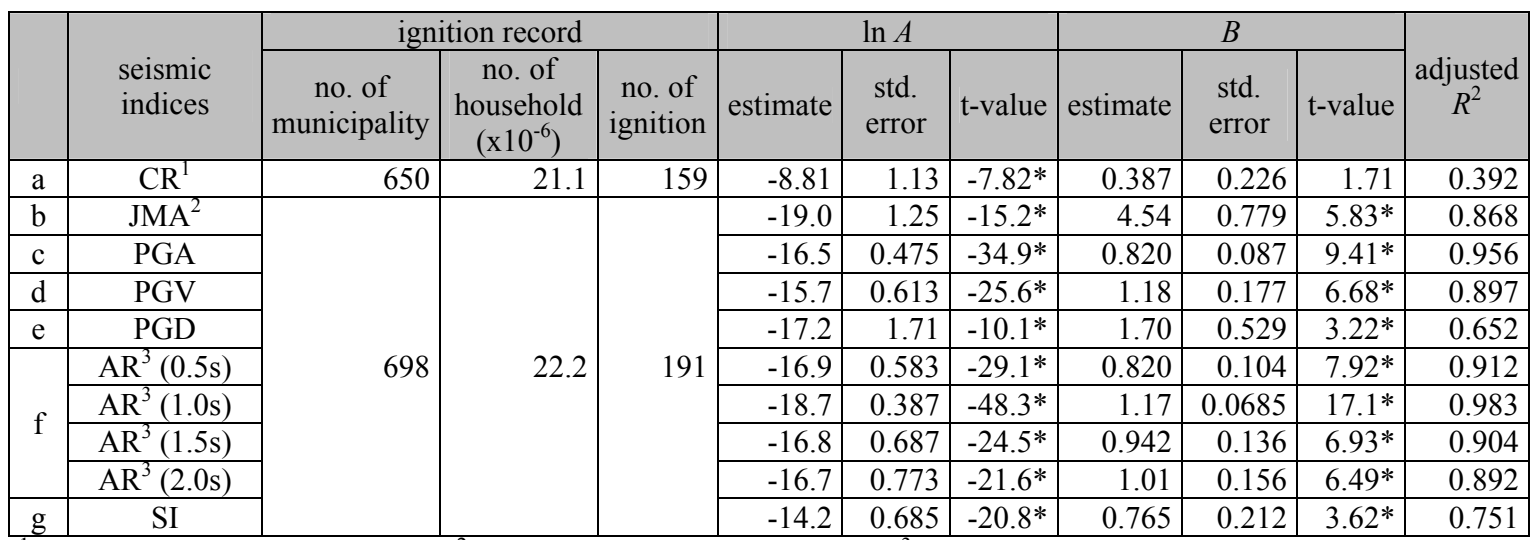

CR: collapse ratio of houses ${ }^{2}$ JMA: JMA seismic intensity ${ }^{3}$ AR: acceleration response

* t-value below 5\% significance level

Table 4. Results of the regression analysis (1995 Kobe earthquake).

\begin{tabular}{|c|c|c|c|c|c|c|c|c|c|c|c|}
\hline & \multirow[b]{2}{*}{$\begin{array}{l}\text { seismic } \\
\text { indices }\end{array}$} & \multicolumn{3}{|c|}{ ignition record } & \multicolumn{3}{|c|}{$\ln A$} & \multicolumn{3}{|c|}{$B$} & \multirow[b]{2}{*}{$\begin{array}{c}\text { adjusted } \\
R^{2}\end{array}$} \\
\hline & & $\begin{array}{c}\text { no. of } \\
\text { municipality }\end{array}$ & $\begin{array}{c}\text { no. of } \\
\text { household } \\
\left(\mathrm{x} 10^{-6}\right)\end{array}$ & $\begin{array}{c}\text { no. of } \\
\text { ignition }\end{array}$ & estimate & $\begin{array}{l}\text { std. } \\
\text { error }\end{array}$ & t-value & estimate & $\begin{array}{l}\text { std. } \\
\text { error }\end{array}$ & t-value & \\
\hline $\mathrm{a}$ & $\mathrm{CR}^{1}$ & \multirow{2}{*}{134} & \multirow{2}{*}{8.6} & \multirow{2}{*}{285} & -6.48 & 0.702 & $-9.23 *$ & 0.903 & 0.164 & $5.50 *$ & 0.880 \\
\hline $\mathrm{d}$ & PGV & & & & -19.2 & 0.879 & $-21.9 *$ & 2.29 & 0.225 & $10.2^{*}$ & 0.954 \\
\hline
\end{tabular}

CR: collapse ratio of houses $*$ t-value below $5 \%$ significance level 
ratio of houses), t-values were the significance level of 5\%. Although most of adjusted determination coefficients $R^{2}$ were high, those of CR and PGD were below 0.7. Adjusted determination coefficients $R^{2}$ of AR (acceleration response) were high for all four representative periods $(T=0.5,1.0,1.5$, and $2.0 \mathrm{~s})$. Original intent of analyzing AR was to see whether there is any specific period $T$ which can correlate ignition probability $p$ better. Among the four periods, $R^{2}$ was the highest for $T=1.0 \mathrm{~s}$. As suggested by Sakai, AR with period $T$ shorter than 1 second has a good correlation with damage of non-structural members, and AR with period $\mathrm{T}$ between 1 to 2 seconds has a good correlation with damage of structural members [5]. Present result shows that ignition probability $p$ in the Tohoku event was sensitive to the period $T$ on the boundary. However, because ignition records were categorized into several classes of seismic intensity $\theta$, it is difficult to judge how well the difference of spectral form between municipalities represented in this

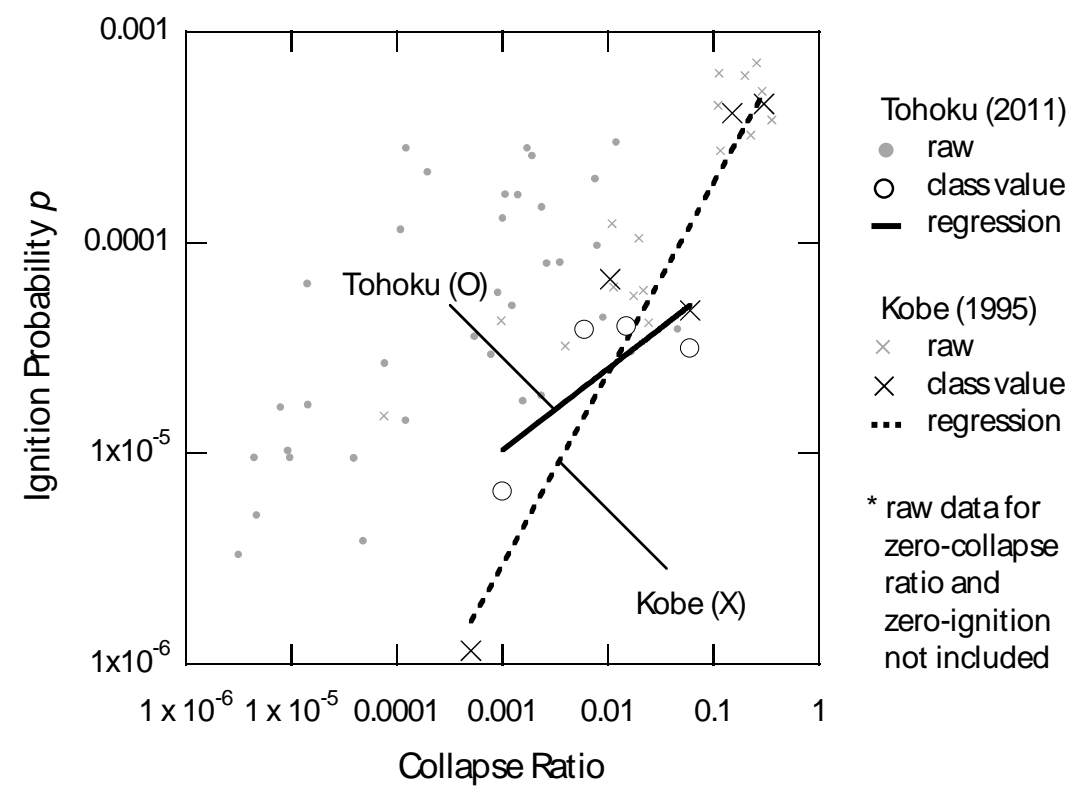

Fig. 9. Probability of earthquake-generated ignition (collapse ratio).

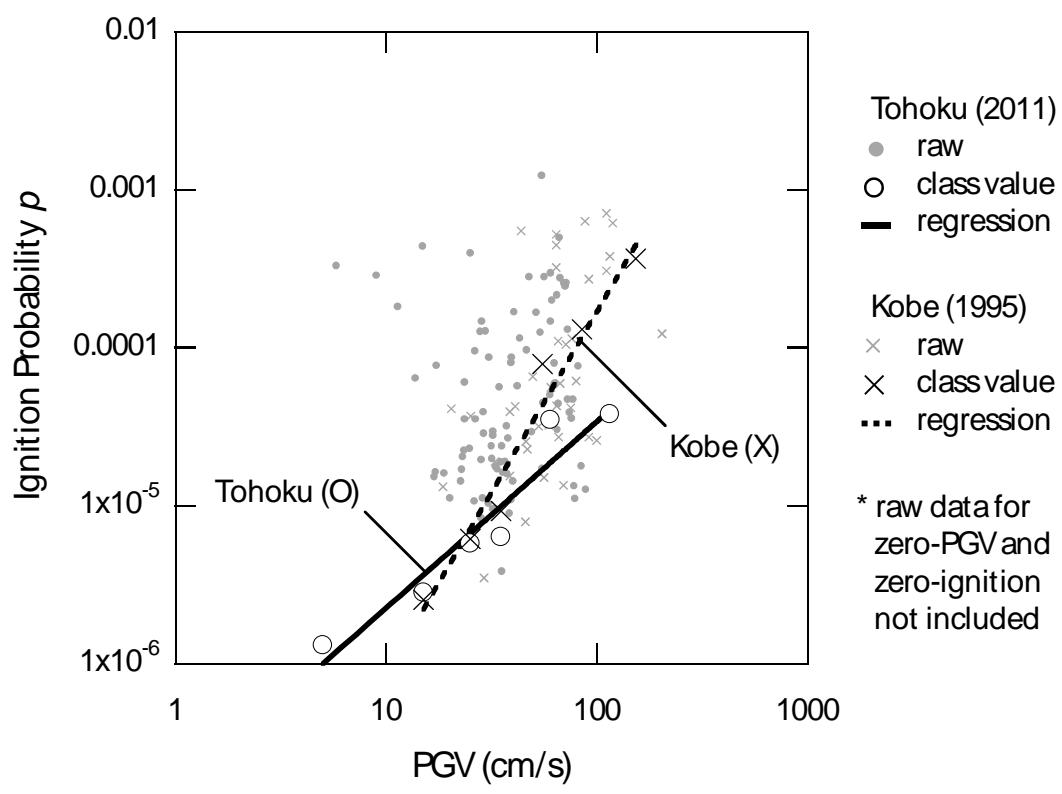

Fig. 10. Probability of earthquake-generated ignition (PGV). 
analysis. This will need further analysis before arriving at a conclusion.

In order to elucidate the features of ignition probability $p$ of the Tohoku earthquake, similar regression analysis was conducted for the ignitions of the Kobe earthquake. The result is shown in Table 4. For both $\mathrm{CR}$ and PGV, t-values of coefficients $A$ and $B$ were below the significance level of 5\%. Adjusted determination coefficients $R^{2}$ were also high. Comparison of the results between the Tohoku and Kobe earthquakes are illustrated in Figs. 9 and 10. However, because ignition records of zero-ignition and zeroseismic-intensity are not included in Figs. 9 and 10, plots of raw ignition records are shifted upward from the class values. There is a similar trend for CR and PGV, i.e., ignition probability $p$ of the Tohoku earthquake is higher than that of the Kobe earthquake for the lower seismic scale $\theta$, but it switches around for the higher $\theta$. In other words, gradient of the regression equation of $p$ for the Tohoku earthquake is smaller than that of the Kobe earthquake. On the other hand, the fact that the regression equations crossed each other for both CR and PGV suggests that ignition probabilities $p$ of the Tohoku and Kobe earthquakes are close to each other. To add, the similar trend for CR and PGV partly supports the reasonableness of the result of the collapse ratio even though its adjusted determination coefficients $R^{2}$ was low for the Tohoku earthquake.

\section{Normalization of the Model}

One of the major factors which affect ignition probability $p$ is the date and time at which an earthquake occurs. Generally, high ignition probability $p$ is expected at early-evening of winter when usage rate of heating and cooking appliances is high. Because the conditions are not the same between the Tohoku and Kobe earthquakes, obtained regression results cannot be compared directly. Thus they were normalized by

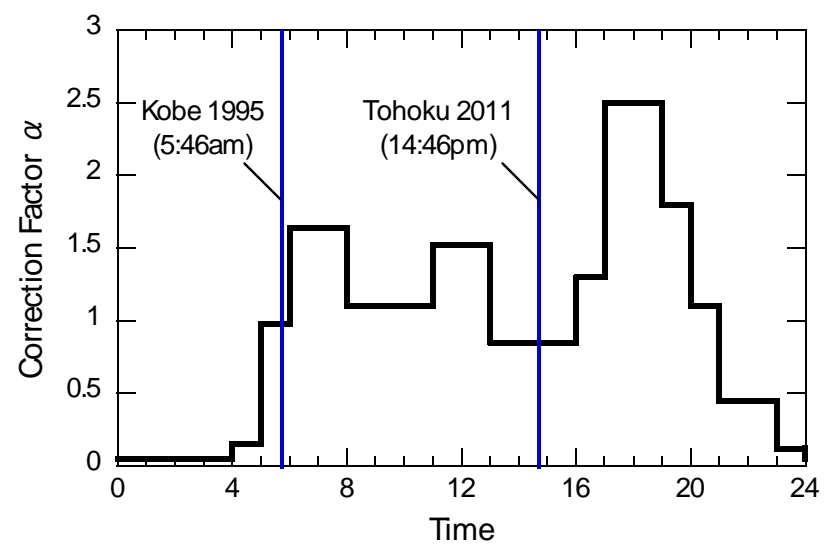

Fig. 11. Time correction factor $\alpha$.

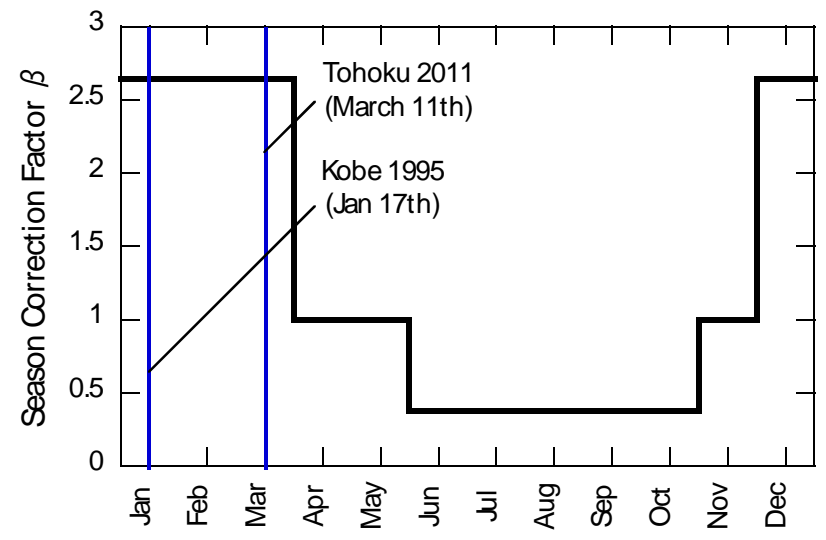

Fig. 12. Season correction factor $\beta$. 
adjusting correction factors proposed by Mizuno [8]. As referred to Eqs.(2) and (3), he incorporated the time correction factor $\alpha$, and the season correction factor $\beta$ into Kawasumi model. Values of the correction factors are shown in Figs.11 and 12. Relevant values of the time correction factor $\alpha$ were 0.85 for the Tohoku earthquake and 0.98 for the Kobe earthquake. Those of the season correction factor $\beta$ were 2.65 for both earthquakes. The regression equations were normalized to that of a hypothetical earthquake occurring at Jan $1^{\text {st }} 12: 00 \mathrm{pm}$, at which the time correction factor $\alpha$ is 1.52 and the season correction factor $\beta$ is 2.65. The base regression equations for CR (collapse ratio of houses) and PGV are overlaid with the normalized regression equations in Fig. 14 and 15, respectively.

Due to the normalization, ignition probabilities $p$ became higher than those of base regression equations for both the Tohoku and Kobe earthquakes. However, because the extents of normalization were comparable

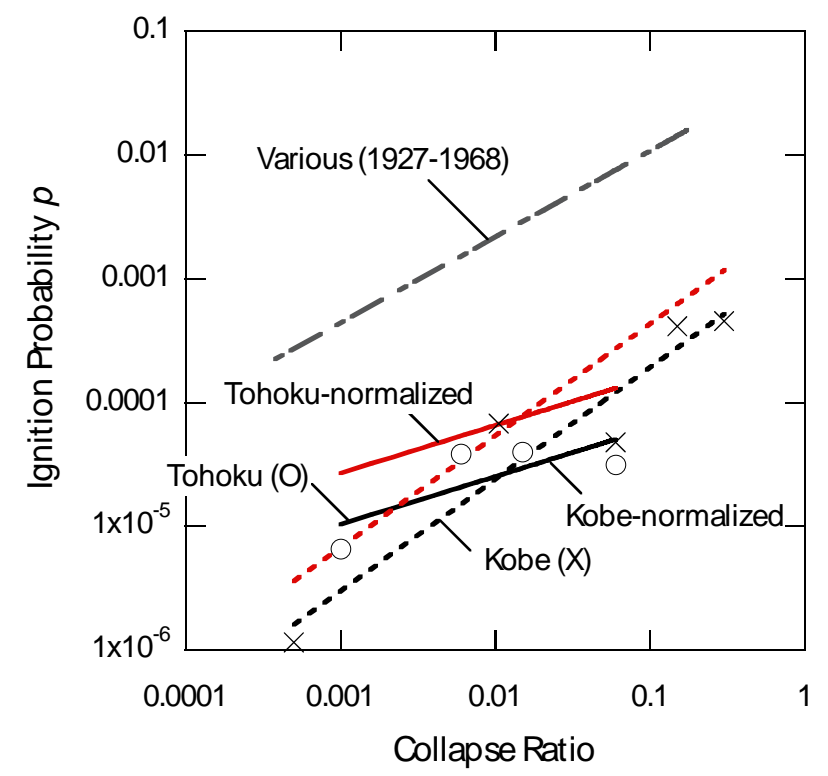

Fig. 13. Normalized probability of earthquake-generated ignition (collapse ratio).

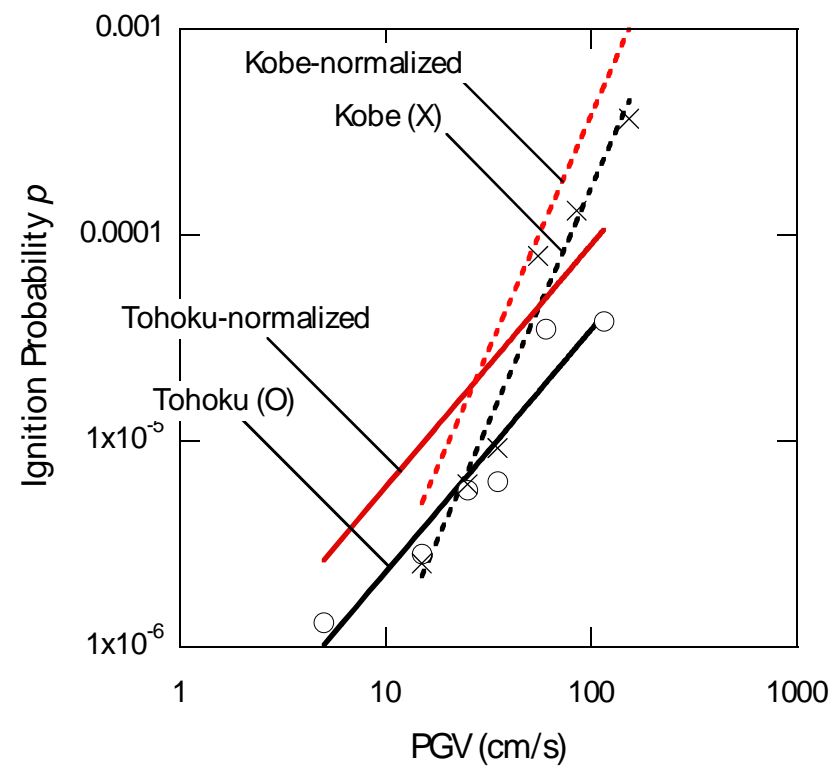

Fig. 14. Normalized probability of earthquake-generated ignition (PGV). 
between two earthquakes, i.e., normalization factor was 1.79 for the Tohoku earthquake and 1.55 for the Kobe earthquake, notable change did not appear in their relationships. For comparison, the normalized regression equation of collapse ratio of houses for various earthquakes (Tango 1927, Nankai 1946, Tokachi 1952, Ebino 1968 and Tokachi 1968) is added to Fig.14 [9]. The comparison result indicates that the ignition probability $p$ of various earthquakes between 1927 and 1968 is substantially higher than those of Kobe earthquake 1995 and Tohoku earthquake 2011. One of the differences between various earthquakes, and the Kobe and Tohoku earthquakes is that the country experienced a high economic growth in the middle of $20^{\text {th }}$ century. From then after, heating and cooking appliances in houses became modernized and the usage frequency of open flame reduced. As a consequence, cause of ignitions changed from the early to middle of $20^{\text {th }}$ century to then after.

\section{CONCLUSIONS}

In this study, relationship between the ignition probability $p$ and the scale of several seismic indices $\theta$ in the the Tohoku earthquake event was analyzed. Seismic indices $\theta$ used in this analysis were (a) collapse ratio of houses, (b) JMA seismic intensity, (c) PGA, (d) PGV, (e) PGD, (f) acceleration response and (g) SI. Obtained adjusted determination coefficients were higher than 0.7 for most of the seismic indices $\theta$ except for (a) collapse ratio of houses and (e) PGD. After normalization with regard to time and season of its occurrence, the results were further compared with that of various earthquakes (1927-1968), and the Kobe earthquake (1995). Ignition probability $p$ of the Tohoku earthquake (2011) was substantially lower than that of the various earthquakes (1927-1968). On the other hand, the difference of ignition probability $p$ between the Tohoku earthquake (2011) and Kobe earthquake (1995) was relatively small. The analysis was conducted using a simple one-parameter model formerly proposed by Kawasumi. Although ignition probability $p$ was successfully modeled using Kawasumi model, ignition behavior is also subject to factors other than seismic indices $\theta$. For example, ignition probability may change between different city zones (residential, commercial, industrial, etc.), because there are different potential causes of ignition in different city zones. Analysis of detailed ignition behavior will be the future work of this study.

\section{REFERENCES}

[1] Japan Meteorological Agency, Report of the 2011 Off the Pacific Coast of Tohoku Earthquake, Technical Report of the Japan Meteorological Agency, No.133, 2012.

[2] Fire and Disaster Management Agency, $147^{\text {th }}$ Report of the 2011 Off the Pacific Coast of Tohoku Earthquake, 2013.

[3] Scawthorn, C., "Historical Fires Following Earthquakes", Fire Following Earthquake, Scawthorn, C., Eidinger, J.M., Schiff, A.J. (ed.), Technical Council on Lifeline Earthquake Engineering, Monograph No.26, American Society of Civil Engineers, 2005.

[4] Fire and Disaster Management Agency, Report of the 1995 Hyogo-ken Nanbu Earthquake, 2006.

[5] Sakai, A., "Correspondence of Strong Ground Motions and Damage to Houses and Buildings in the 2011 Tohoku-chiho Taiheiyo-oki Earthquake", Journal of Structural and Construction Engineering, Architectural Institute of Japan, Vol.78, No.683, pp.35-40, 2013.

[6] Tokyo Metropolitan Government, Assessment of Loss due to Post-earthquake Fires in the Tokyo Metropolitan Area, 1961.

[7] Aoki, Y., "Stochastic Theory on Outbreaks of Fire Following Earthquake", Journal of Architectural Planning and Environmental Engineering, Architectural Institute of Japan, No.412, pp.53-60, 1990.

[8] Mizuno, H., and Horiuchi, S., "Study on the Relationship between the Ratio of the Outbreak of Fires and that of the Totally Destroyed Dwelling Houses Caused by the Earthquakes", Bulletin of AIJ, Architectural Institute of Japan, No.247, pp.101-110, 1976.

[9] Building Research Institute, Prediction of Breakout and Spread of Seismic City Fire, Report of the Building Research Institute, No.102, 1983. 
[10] Butterworth, S., "On the theory of filter amplifiers", Experimental Wireless and the Wireless Engineer, vol.7, pp. 536-541, 1930.

[11] Si, H., and Midorikawa, S., "New Attenuation Relationships for Peak Ground Acceleration and Velocity Considering Effect of Fault Type and Site Condition, Journal of Structural and Construction Engineering, Architectural Institute of Japan, No.523, pp.63-70, 1999.

[12] Fijiwara, H., Kawai, S., Aoi, T., Ishii, T., Hayakawa, Y., Kunugi, T., Jinno, T., Morikawa, N., Kobayashi, K., and Hara, A., Study on Preliminary Versions of Probabilistic Seismic Hazard Map, Technical Note of the National Research Institute for Earth Science and Disaster Prevention, No.236, 2002.

[13] Housner, G.W., "Spectrum intensities of strong-motion earthquakes", Symposium on Earthquakes and Blast Effects on Structures, Los Angeles, CA, 1952.

[14] Nakamura, Y., "Comparison of Various Earthquake Motion Indices”, Journal of Japan Association for Earthquake Engineering, Vol.7, No.2, pp.235-248, 2007. 